\title{
INFLUÊNCIA DOS COMBUSTÍVEIS AUTOMOTIVOS NO MATERIAL PARTICULADO ATMOSFÉRICO DE SÃO PAULO E RIO DE JANEIRO
}

\author{
Pedro Caffaro Vicentini ${ }^{1}$, Tadeu Cavalcante Cordeiro de Melo ${ }^{1}$, Luciana Neves Loureiro ${ }^{1}$, \\ Márcia Figueiredo Moreira ${ }^{1}$ e Nelson da Silva Alves ${ }^{1}$ \\ ${ }^{1}$ PETROBRAS \\ E-mails: pcvicentini@petrobras.com.br, tcm@petrobras.com.br,

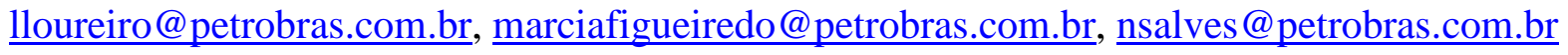

\section{RESUMO}

São apresentados os resultados de um estudo realizado pela Petrobras, USP e PUC-RJ para determinar a influência das principais fontes na formação do material particulado (MP) nas regiões metropolitanas de São Paulo e Rio de Janeiro, em especial o $\mathrm{MP}_{2,5}$. Um dos objetivos foi a caracterização completa do MP presente no gás de escapamento de veículos típicos da frota brasileira. Utilizando técnicas de amostragem e medição inovadoras, foram testados combustíveis com diversos teores de enxofre em veículos leves (ciclo Otto e ciclo Diesel), ciclomotores e motores pesados a diesel. Durante um ano fez-se a coleta de MP ambiental em oito estações de monitoramento, quatro em cada metrópole. Técnicas avançadas de análise foram empregadas para caracterizar o material particulado coletado. Na sequência, foram utilizadas técnicas de estatística multivariada para quantificar a participação de certas tipologias de fontes de poluentes. Os resultados obtidos mostraram que, nos últimos anos, a qualidade do ar não sofreu alteração importante nas metrópoles estudadas, o que pode ser creditado à evolução nas tecnologias veiculares e nos combustíveis, além da renovação da frota. Com relação à contribuição dos combustíveis automotivos na formação do $\mathrm{MP}_{2,5}$ atmosférico, verificou-se que esta é de cerca de $60 \%$ nos dois centros, considerando as emissões diretas e os aerossóis secundários, a maior parte dos quais pode ser atribuída a reações em que participam compostos orgânicos de origem veicular.

\section{INTRODUÇÃO}

Sabe-se que as emissões veiculares são uma das principais fontes de material particulado nas grandes cidades. Nesse sentido, seguindo a tendência dos países mais desenvolvidos, a legislação brasileira através do PROCONVE (Programa de Controle da Poluição do Ar por Veículos Automotores) vem estabelecendo limites cada vez mais restritivos para o material particulado e outros poluentes presentes nas emissões veiculares (hidrocarbonetos, monóxido de carbono, óxidos de nitrogênio e aldeídos). Dessa forma, espera-se evitar que o crescimento acelerado da frota proporcione uma deterioração da qualidade do ar, principalmente nos grandes centros urbanos.

Em 2011, a Petrobras firmou um Termo de Cooperação com as universidades USP e PUC-RJ para estudar a influência das principais fontes emissoras na formação de material particulado (MP), em especial o $\mathrm{MP}_{2,5}$ (material particulado com diâmetro inferior a 2,5 $\mu \mathrm{m}$ ). Essa 
iniciativa foi denominada "Projeto Fontes", tendo sido desenhada com o desafio de empregar as melhores técnicas disponíveis para o estudo do aerossol ambiental.

Um dos objetivos específicos do projeto foi a caracterização do MP coletado do gás de escapamento de veículos típicos da frota a diesel, a gasolina e a etanol. Para tal, foram selecionados veículos leves (ciclo Otto e ciclo Diesel), ciclomotores e motores pesados a diesel, sendo os mesmos testados no Centro de Pesquisas da Petrobras (CENPES) e no Instituto de Tecnologia para o Desenvolvimento, no Paraná (LACTEC). Além de metodologias padronizadas para a realização desses ensaios, foram utilizados equipamentos de medição de última geração para a determinação qualitativa e quantitativa do perfil de emissões de material particulado.

Outro objetivo foi determinar o impacto do MP de origem veicular na qualidade do ar nas regiões metropolitanas de São Paulo e do Rio de Janeiro. Para tal, durante cerca de um ano fez-se a coleta de MP ambiental utilizando-se quatro estações de monitoramento em cada uma das regiões. Técnicas avançadas de amostragem e de análise foram utilizadas para caracterizar o material particulado coletado, tais como, a espectrometria de massa dos aerossóis e a determinação do carbono orgânico por análise térmica diferencial, técnicas essas inovadoras no Brasil. Uma grande variedade de metais pesados, compostos de enxofre, compostos orgânicos voláteis e outros poluentes foram analisados por modelos receptores estatísticos e de balanço de massa, visando à identificação de marcadores e vinculação das fontes de poluentes.

\section{METODOLOGIA}

\subsection{Coleta do MP veicular}

O objetivo dessa etapa do projeto foi contribuir para a caracterização da emissão de material particulado associado à combustão dos motores utilizados pela frota veicular brasileira. Para tanto, foram coletadas em laboratório amostras de material particulado proveniente do gás de escapamento de diversos tipos de veículos e motores testados em dinamômetro.

\subsubsection{Veículos, motores e combustíveis de teste}

Foram selecionados 11 veículos de passeio do ciclo Otto, 3 veículos leves a diesel, 4 motocicletas e 3 motores pesados a diesel. Dos veículos de passeio, 1 era a etanol, 4 eram flexfuel e 6 eram a gasolina, sendo que em um destes havia um kit GNV instalado. Os 3 veículos leves a diesel era do tipo sport utility (SUVs). Das mocicletas, 3 eram a gasolina e uma era flexfuel.

As amostras foram coletadas no Centro de Pesquisas da Petrobras (CENPES) e no Instituto de Tecnologia para o Desenvolvimento (LACTEC) localizado no Paraná. Os veículos foram testados com combustíveis comerciais (gasolina C, etanol hidratado, GNV e diesel) que atendiam às especificações estabelecidas pela ANP vigentes à época. Ressalta-se que, durante a coleta de amostras ambientais ( $2^{\circ}$ semestre de 2012 e $1^{\circ}$ de 2013), o diesel metropolitano S50 foi substituído pelo S10, e por isso foram testados os dois produtos, além do diesel S500.

A Tabela 1 apresenta o quantitativo de veículos testados por fase do PROCONVE/PROMOT, enquanto na Tabela 2 são relacionados os combustíveis de teste utilizados. 
Tabela 1: Veículos e motores testados

\begin{tabular}{|c|c|c|c|}
\hline $\begin{array}{c}\text { Fase do PROCONVE/ } \\
\text { PROMOT }\end{array}$ & Tipo & Combustível & $\begin{array}{c}\text { Tamanho } \\
\text { da amostra }\end{array}$ \\
\hline PRÉ-PROCONVE & veículo de passageiro & etanol & 1 \\
\hline L3 & veículo de passageiro & gasolina & 3 \\
\hline L3 & SUV & diesel & 1 \\
\hline L4 & veículo de passageiro & gasolina & 1 \\
\hline L4 & veículo de passageiro & flex (gasolina/etanol) & 1 \\
\hline L4 & veículo de passageiro & gasolina/GNV & 1 \\
\hline L4 & SUV & diesel & 3 \\
\hline L5 & veículo de passageiro & flex (gasolina/etanol) & 1 \\
\hline L6 & SUV & diesel & 1 \\
\hline M1 & motocicleta & gasolina & 1 \\
\hline M2 & motocicleta & gasolina & 1 \\
\hline M3 & motocicleta & gasolina & 1 \\
\hline M3 & motocicleta & flex (gasolina/etanol) & 1 \\
\hline P4 & motor pesado & diesel & 1 \\
\hline P5 & motor pesado & diesel & diesel \\
\hline P7 & & & \\
\hline
\end{tabular}

Tabela 2: Combustíveis de teste

\begin{tabular}{|c|c|}
\hline Combustível & Características \\
\hline Etanol Hidratado & $\begin{array}{l}\text { Produto comercial atendendo às especificações da Resolução ANP } \mathrm{n}^{\circ} \\
7 \text {, de } 9-2-2011 \text {, contendo } 5,7 \% \mathrm{v} / \mathrm{v} \text { de água. }\end{array}$ \\
\hline Gasolina E22 S800 & $\begin{array}{l}\text { Produto com teor máximo de } 800 \text { ppm de enxofre. atendendo às } \\
\text { especificações então vigentes na Resolução ANP n }{ }^{\circ} 57 \text {, de } 20-10-2011 \text {, } \\
\text { para gasolina comercial. O teor de etanol anidro na mistura foi } \\
\text { estabelecido como sendo igual ao da Gasolina Padrão }(22 \% \mathrm{v} / \mathrm{v}) \text {. }\end{array}$ \\
\hline GNV & Produto atendendo às especificações da Resolução ANP no 16/2008. \\
\hline Diesel S500 & $\begin{array}{l}\text { Combustível comercial com teor máximo de } 500 \text { ppm de enxofre, } \\
\text { atendendo às especificações da Resolução ANP nº } 65 \text {, de } 9-12-2011 \text {. } \\
\text { Possuía a participação de } 5 \% \text { v/v de biodiesel, conforme estabelecido à } \\
\text { época pela legislação. }\end{array}$ \\
\hline Diesel S50 & $\begin{array}{l}\text { Combustível comercial com teor máximo de } 50 \text { ppm de enxofre, } \\
\text { atendendo às especificações da Resolução ANP } \mathrm{n}^{\circ} \text { 65, de 9-12-2011. } \\
\text { Possuía a participação de } 5 \% \text { v/v de biodiesel, conforme estabelecido à } \\
\text { época pela legislação. A amostra correspondia ao diesel metropolitano } \\
\text { que era distribuído para motores P7 em SP e RJ em 2012, ano em que } \\
\text { se iniciaram as coletas ambientais do projeto. }\end{array}$ \\
\hline Diesel S10 & $\begin{array}{l}\text { Combustível comercial com teor máximo de } 10 \text { ppm de enxofre, } \\
\text { atendendo às especificações da Resolução ANP } \mathrm{n}^{\circ} \text { 65, de 9-12-2011. } \\
\text { Possuía a participação de 5\%v/v de biodiesel, conforme estabelecido à } \\
\text { época pela legislação. A amostra correspondia ao diesel metropolitano } \\
\text { que era distribuído para motores P7 em SP e RJ em 2013, ano em que } \\
\text { se encerraram as coletas ambientais do projeto. }\end{array}$ \\
\hline
\end{tabular}

Para estes veículos e combustíveis, determinou-se as taxas de emissões de compostos orgânicos e inorgânicos, assim como dos compostos constituintes do material particulado 
coletado. Os resultados obtidos foram comparados entre si a fim de identificar possíveis traçadores elementares para as emissões de cada combustível.

\subsubsection{Protocolos de teste}

Os ensaios de emissões de veículos leves em dinamômetro de chassi foram realizados seguindo a norma NBR 6601[1], enquanto para motocicletas utilizou-se como referência a diretiva europeia $\mathrm{n}^{\circ}$ 97/24/EC [2].

Para a coleta do MP no gás de escapamento desses veículos, foi instalado na linha do amostrador de volume constante (AVC) um sistema de amostragem contendo um dispositivo chamado very sharp cutter, que permite a passagem de partículas com diâmetro igual ou inferior a 2,5 $\mu \mathrm{m}$, seguido de um suporte contendo um filtro Nuclepore (Figura 1). O conjunto foi conectado a uma bomba de vácuo funcionando a uma vazão de $17 \mathrm{~L} / \mathrm{min}$. Paralelamente a esse sistema, foi instalado um outro idêntico, porém, com um filtro de quartzo.

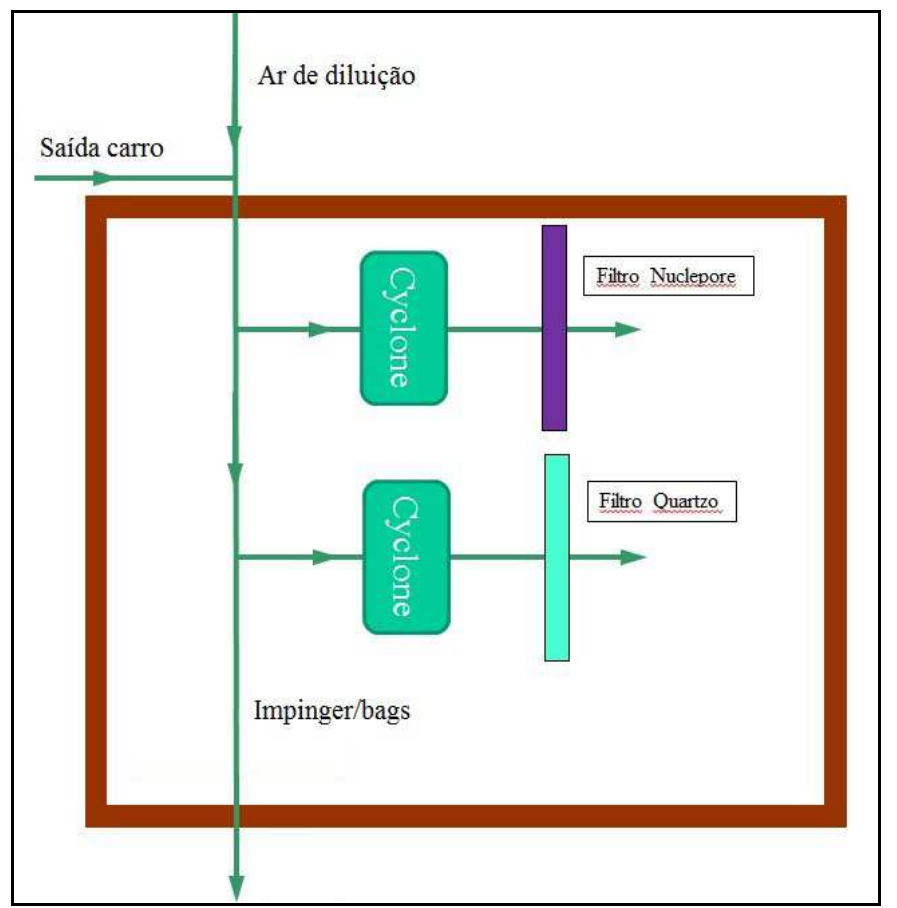

Figura 1 - Esquema do amostrador de material particulado

Sabia-se que quantidade de material particulado emitido pelos veículos e motocicletas testados seria bastante pequena, no etanto havia a necessidade de acumular de uma quantidade de massa razoável nos filtros para tornar possíveis as análises subsequentes. Sendo assim, realizou-se uma sequência ininterrupta de 10 ciclos FTP-74 (equivalentes às fases 1 e 2 do ciclo da norma NBR 6601) nos veículos a gasolina e/ou etanol, e dois ciclos para as SUVs. Para cada motocicleta, foram executados 12 ciclos completos ECE-40.

Foram utilizados o ciclo R49 da norma NBR 14489 [3] para o motor CONAMA P4 e o ciclo ESC da norma NBR 15634 [4] para os motores CONAMA P5 e P7. Como a quantidade de MP no sistema amostrador (smart sampler) era suficiente para as análises, foram realizados apenas dois ensaios com cada conjunto motor-combustível: um utilizando um filtro de Nuclepore e outro com um filtro de quartzo especialmente selecionado para esse fim. 


\subsection{COLETA DE AMOSTRAS AMBIENTAIS}

Durante o segundo semestre de 2012 e o primeiro de 2013, realizou-se a coleta de material particulado para a análise detalhada de sua composição e propriedades físico-químicas. Foram utilizadas 4 estações de monitoramento na região metropolitana de São Paulo e 4 estações na região metropolitana do Rio de Janeiro. As figuras 2 e 3 apresentam aspectos da localização dessas estações.

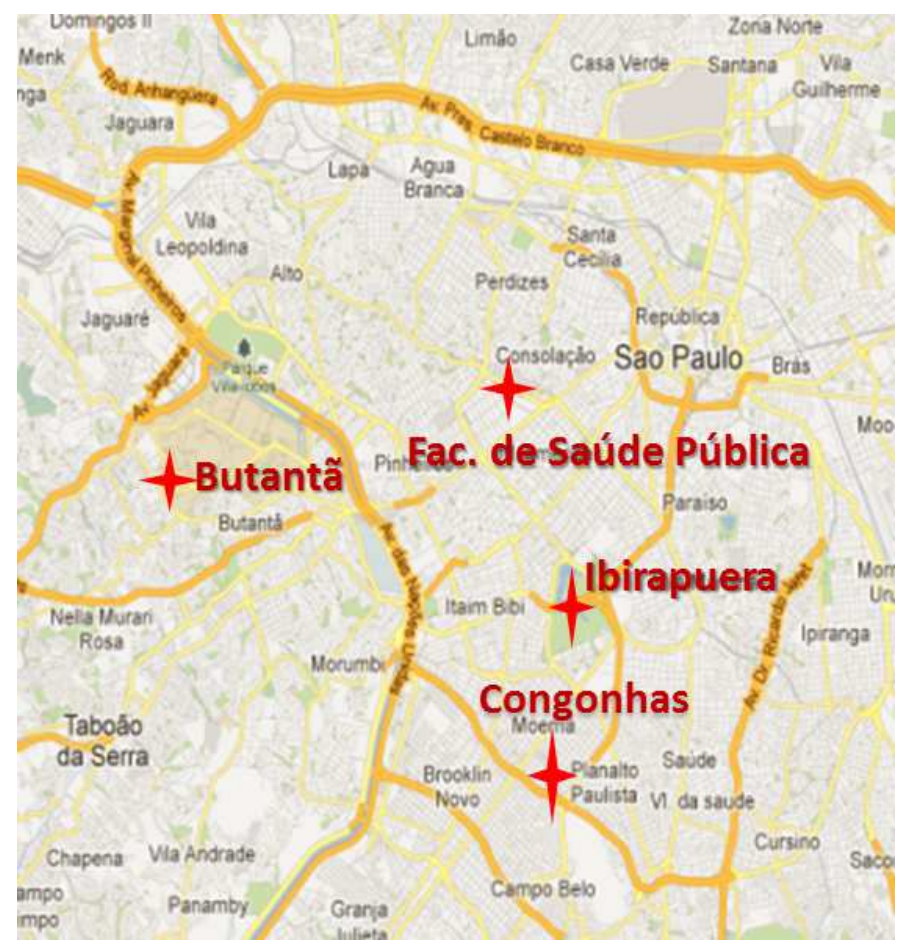

Figura 2 - Estações de coleta de MP em São Paulo.
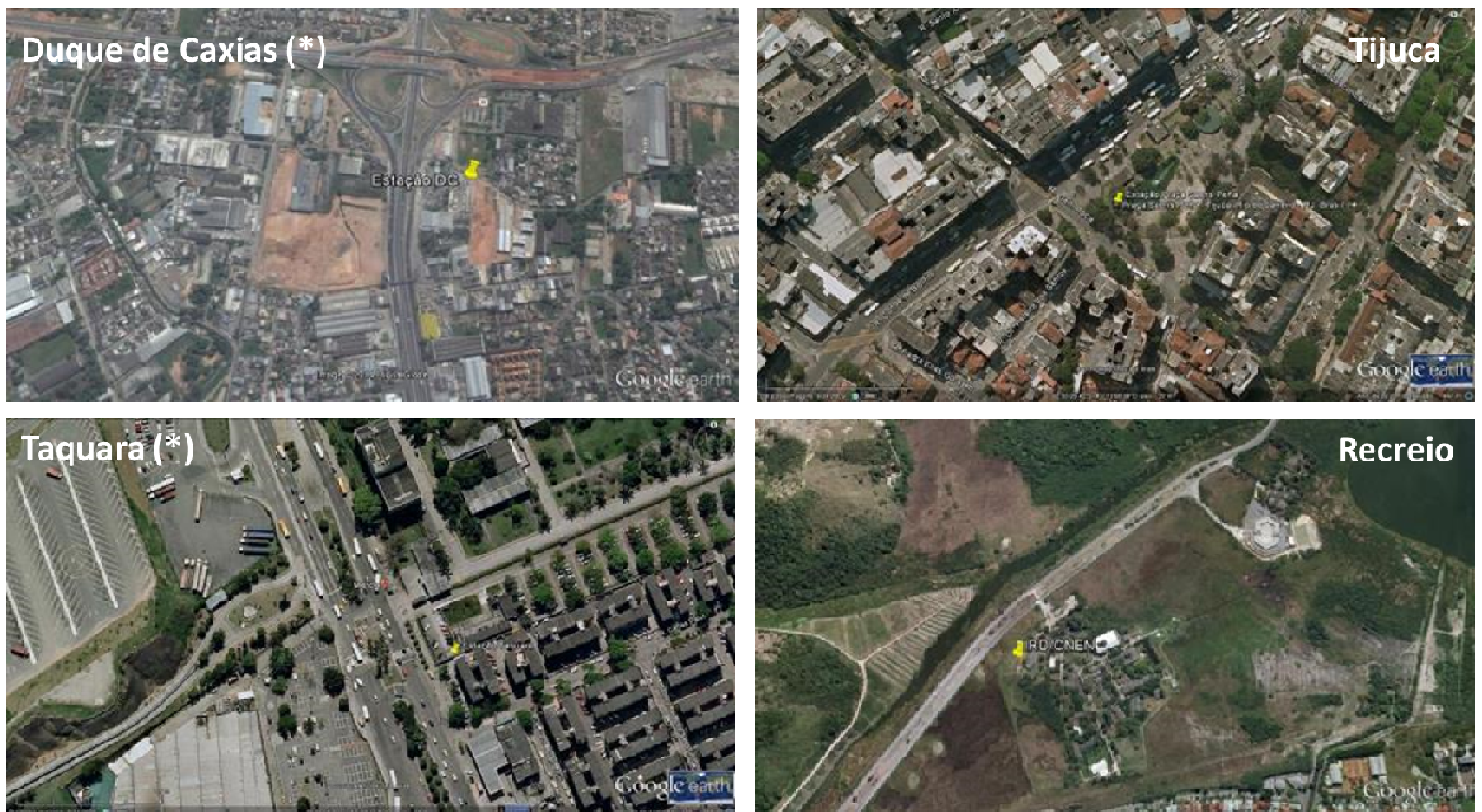

Figura 3 - Estações de coleta de MP no Rio de Janeiro. 
A localização das estações foi definida em parceria com a CETESB (SP) e o INEA (RJ). Em São Paulo, as estações escolhidas para a coleta estavam localizadas nos bairros do Butantã, Consolação, Ibirapuera e Congonhas. E, no Rio de Janeiroe nos bairros da Taquara, Recreio dos Bandeirantes, Tijuca além de uma instalada no Município de Duque de Caxias. Essas estações foram escolhidas por guardarem entre si características diversas em relação à proximidade de vias de trânsito veicular, tipo de tráfego, distância para o mar (no Rio de Janeiro), nível de urbanização, regime de ventos e altura de coleta do MP.

A partir das amostras coletadas nas estações, foi obtida a composição orgânica e inorgânica do material particulado emitido primariamente ou formado secundariamente na atmosfera. As amostragens foram realizadas para um período de 24 horas, com troca dos filtros a cada três dias, compreendendo um total de 122 amostras coletadas em cada estação.

O material particulado fino (diâmetro de particula $<2,5 \mu \mathrm{m}$ ) e o grosso (diametro de particula entre 2,5 e $10 \mu \mathrm{m}$ ) foram coletadas por meio de um sistema de filtros em série chamado Amostrador de Particulado Fino e Grosso (AFG), também conhecido como Stacked Filter Unit (SFU), que utiliza uma entrada com diâmetro de corte de $10 \mu \mathrm{m}$. O AFG coleta as partículas grossas $(2,5<\mathrm{dp}<10 \mu \mathrm{m})$ em um filtro Nuclepore de diâmetro de $47 \mathrm{~mm}$ e $8 \mu \mathrm{m}$ de tamanho dos poros, enquanto um filtro Nuclepore com $0,4 \mu \mathrm{m}$ de tamanho de poros recolhe as partículas finas $(\mathrm{dp}<2.5 \mu \mathrm{m})$. A soma de ambas as frações refere-se a partículas com diâmetro aerodinâmico inferior a $10 \mu \mathrm{m}\left(\mathrm{MP}_{10}\right)$. $\mathrm{O}$ volume de amostragem é registrado num integrador de volume, calibrado com um padrão primário de fluxo de ar. A Figura 4 ilustra o amostrador AFG utilizado.

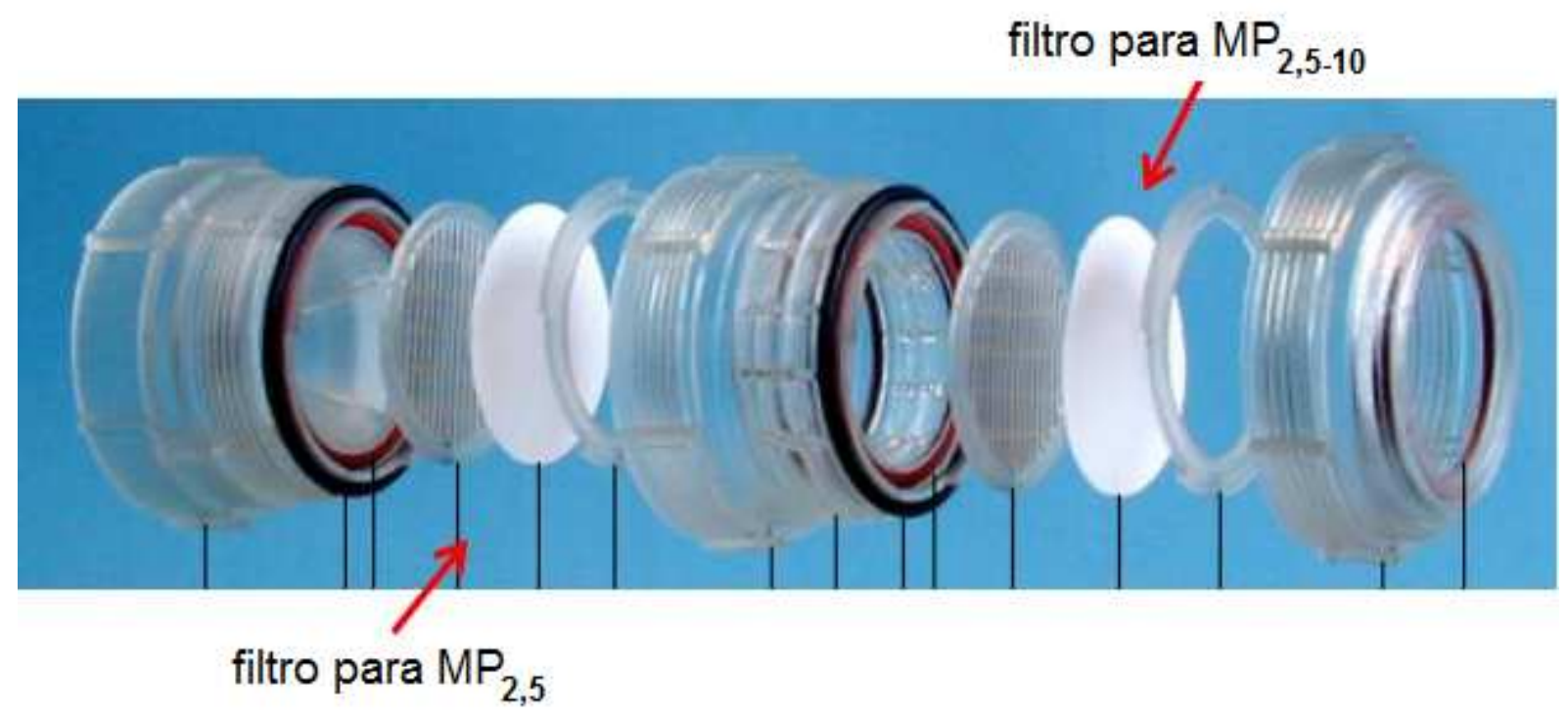

Figura 4: Esquema do amostrador grosso fino (AGF) empregado

Foi utilizado um segundo amostrador em paralelo ao dos filtros Nuclepore para a medida do material carbonáceo menor que $2.5 \mu \mathrm{m}$, equipado com filtros de quartzo para análise quantitativa de carbono orgânico e carbono elementar. Foi utilizado um inlet de corte em $\mathrm{MP}_{2,5}$ para este amostrador. $\mathrm{O}$ conjunto dos dois amostradores em paralelo permitiu a análise de metais, compostos iônicos, carbono orgânico e elementar. 
Além da coleta em filtros, durante cerca de 3 meses em duas estações foi realizada uma análise em tempo real da composição do material particulado, ao mesmo tempo em que se efetuava a especiação dos hidrocarbonetos presentes no ar. Essas medidas foram tomadas nas estações da Consolação (SP) e Taquara (RJ), e visavam estabelecer uma relação entre esses poluentes que ajudasse a identificar marcadores específicos para as emissões advindas da combustão do diesel e da gasolina. Dessa forma, esperava-se separar a influência desses combustíveis no processo de formação do MP ambiental. Para tal foram utilizados os equipamentos: Aerosol Mass Spectrometry (AMS), da Aerodyne Inc. e o Proton Mass Transfer Reaction Smepectrotry (PTR-MS), cuja a descrição é melhor detalhada no item 1.3.

\subsection{TÉCNICAS ANALÍTICAS.}

A massa de material particulado retida nos filtros foi obtida através de análise gravimétrica, utilizando uma micro balança eletrônica com uma sensibilidade de $1 \mu \mathrm{g}$. O limite de detecção em concentração mássica de material particulado foi de cerca de $0,6 \mu \mathrm{g} \mathrm{m}^{-3}$, enquanto que a precisão foi estimada em 5\%. A concentração de carbono elementar (black carbon) na fração fina foi medida usando-se a técnica de refletância.

A fim de determinar a fração solúvel em água e a concentração elementar nos filtros Nuclepore, os mesmos foram divididos em dois pedaços. Em um deles, foram determinados por cromatografia iônica os seguintes compostos: amônio, potássio, sódio, cálcio, magnésio, acetato, formiato, nitrato, sulfato e cloreto. Na outra fração dos filtros, metais e semimetais (Li, Be, Na, Mg, Al, K, Sc, Ti, V, Mn, Fe, Co, Ni, Cu, Zn, Ga, Ge, As, Se, Rb, Sr, Y, Nb, Mo, $\mathrm{Ag}, \mathrm{Cd}, \mathrm{Sb}, \mathrm{Cs}, \mathrm{Ba}, \mathrm{La}, \mathrm{Ce}, \mathrm{Pr}, \mathrm{Nd}, \mathrm{Sm}, \mathrm{Eu}, \mathrm{Gd}, \mathrm{Tb}, \mathrm{Dy}, \mathrm{Ho}, \mathrm{Er}, \mathrm{Tm}, \mathrm{Yb}, \mathrm{Lu}, \mathrm{W}, \mathrm{Pb}, \mathrm{Bi}$, Th e U) foram determinados utilizando-se a técnica de ICP-MS.

Para melhor quantificação de alguns metais, as amostras foram também analisadas pelo método de Fluorescência de Raios-X, através do instrumento PanAnalytical Epsilon 5 [5].

As componentes do carbono orgânico e do elementar foram analisadas através da técnica da análise térmica diferencial, utilizando o instrumento Sunset Instruments [6].

A determinação da composição do aerossol ambiental em tempo real foi feita com o equipamento Aerosol Mass Spectrometer (AMS), da Aerodyne Inc. [7], que permite a medição do espectro orgânico e inorgânico de partículas de aerossóis, possibilitando separar a componente de emissão primária dos compostos formados secundariamente na atmosfera. Em particular, o instrumento separa os compostos orgânicos em oxigenados e hidratados, além dos compostos inorgânicos chaves, tais como nitrato e sulfato.

O instrumento Multi Angle Absorption Photometer (MAAP), modelo 5012 da Thermo Environment [8], mediu em tempo real a concentração de black carbon, com resolução temporal de cerca de 10 minutos.

O instrumento Scanning Mobility Particle Sizer (SMPS) da TSI Inc. [9] mediu a distribuição de tamanho de partículas ultrafinas na faixa de tamanho de 10 a 800 nanômetros. A máxima resolução temporal desse instrumento é de 1 minuto.

A técnica de Proton Mass Transfer Reaction Spectrometry (PTR-MS) [10] possibilitou a detecção de compostos orgânicos voláteis (COV) em tempo real, com limites de detecção de 
menos de 1 ppt para várias espécies, dentre elas: benzeno, acetona, acetaldeido, formaldeido, isopreno, todos os monoterpenos, metanol, 1-3 butadieno, acetonitrila (traçador de queimadas de madeira), acetileno, entre muitos outros compostos, com resolução temporal de minutos.

A qualidade dos dados obtidos dessas análises foi avaliada através de uma grande variedade de técnicas estatísticas. Histogramas, cálculos de fechamento de massa e distribuições normal e log-normal foram gerados para cada variável, a fim de validar os dados coletados. Teve-se também a validação dos dados através da comparação da concentração de vários elementos que foram determinados por diferentes técnicas analíticas.

\subsection{ATRIBUIÇÃO DAS FONTES DE MATERIAL PARTICULADO}

A fim de determinar a participação das fontes veiculares na formação do material particulado fino atmosférico, na terceira fase do projeto, cruzou-se as assinaturas de emissões de MP2,5 dos diferentes veículos testados na primeira fase e a composição das amostras ambientais obtidas na segunda etapa, Uma abordagem estatística multivariada foi aplicada para esse fim, incluindo Análise de Fatores Principais Absoluto, Análise de Fatores Principais Positivada, Análise de Agrupamento Hierárquico e modelos do tipo "Chemical Mass Balance". Para reduzir o número de variáveis incluídas neste estudo, realizou-se uma pré-análise estatística de correlação. Também foram analisadas as variáveis que tinham um número significativo de valores faltantes, e as variáveis não associáveis com as fontes de poluição atmosférica conhecidas.

Técnicas similares foram utilizadas para separar a influência das emissões diretas dos veículos do ciclo Diesel e do ciclo Otto sobre o MP1, utilizando-se as medições efetuadas em tempo real.

\section{RESULTADOS}

\subsection{EMISSÕES VEICULARES DE $\mathrm{MP}_{2,5}$}

Por meio da análise das amostras coletadas nos ensaios em laboratório, foi possível realizar a caracterização completa do material particulado presente no gás de escapamento dos veículos e motores utilizados. Na fase seguinte, os perfis encontrados foram comparados entre si, a fim de encontrar diferenças que pudessem ser atribuídas aos tipos de combustíveis testados.

No caso dos combustíveis usados por veículos do ciclo Otto, não foi possível encontrar diferenças sensíveis entre a composição do MP oriundo da combustão da gasolina e do etanol. Uma possível razão para isso é a elevada participação do etanol na gasolina comercial brasileira. Destaca-se que as diferenças de composição encontradas entre o MP dos diferentes veículos foi maior que a decorrente da utilização de gasolina ou etanol pelos mesmos. No caso de veículos a GNV, a massa de MP coletada foi ínfima, insuficiente para proceder às análises de composição. Dessa forma, não foi possível derivar um perfil característico para a queima desse combustível em motores.

Uma diferença marcante entre a composição do MP emitido por motores a diesel e por veículos a gasolina/etanol é que no primeiro caso a composição é quase que totalmente formado por carbono orgânico e elementar, enquanto no segundo esses compostos respondem 
por cerca da metade da composição. Com relação a outros elementos, observou-se que as maiores diferenças estão na maior emissão de $\mathrm{Fe}, \mathrm{Al}, \mathrm{V}, \mathrm{Cr}$, e Ni, pelos motores a diesel, e Mo, pelos automóveis.

Embora o foco do trabalho fosse a análise qualitativa e não a quantitativa do MP de escapamento, efetuou-se também a comparação entre os fatores de emissão obtidos, a fim de verificar a influência dos combustíveis sobre eles. As figuras 5 a 8 apresentam os resultados encontrados em termos de fatores de emissão para os veículos e motores testados. Destaca-se que os resultados obtidos para a medição de MP em veículos Otto e motocicletas são inéditos no Brasil.

Nos veículos do ciclo Otto (Figura 5), observa-se um valor de MP mais elevado para aqueles da fase L3 do PROCONVE (em média $2,86 \mathrm{mg} / \mathrm{km}$ ) e menores para os das fases L4 e L5, com pouca variação entre ambas as fases (valor médio de $0,97 \mathrm{mg} / \mathrm{km}$ ). Salienta-se que os valores encontrados são bastante próximos aos publicados no inventário oficial de emissões rodoviários do Ministério do Meio Ambiente (MMA) [11], que utilizou um valor de 1,1 $\mathrm{mg} / \mathrm{km}$, baseado em um inventário da Comunidade Europeia. Com etanol, os valores medidos durante o trabalho se apresentaram insensíveis ao tipo de tecnologia veicular testada, oscilando em torno de um valor médio de $0,50 \mathrm{mg} / \mathrm{km}$.

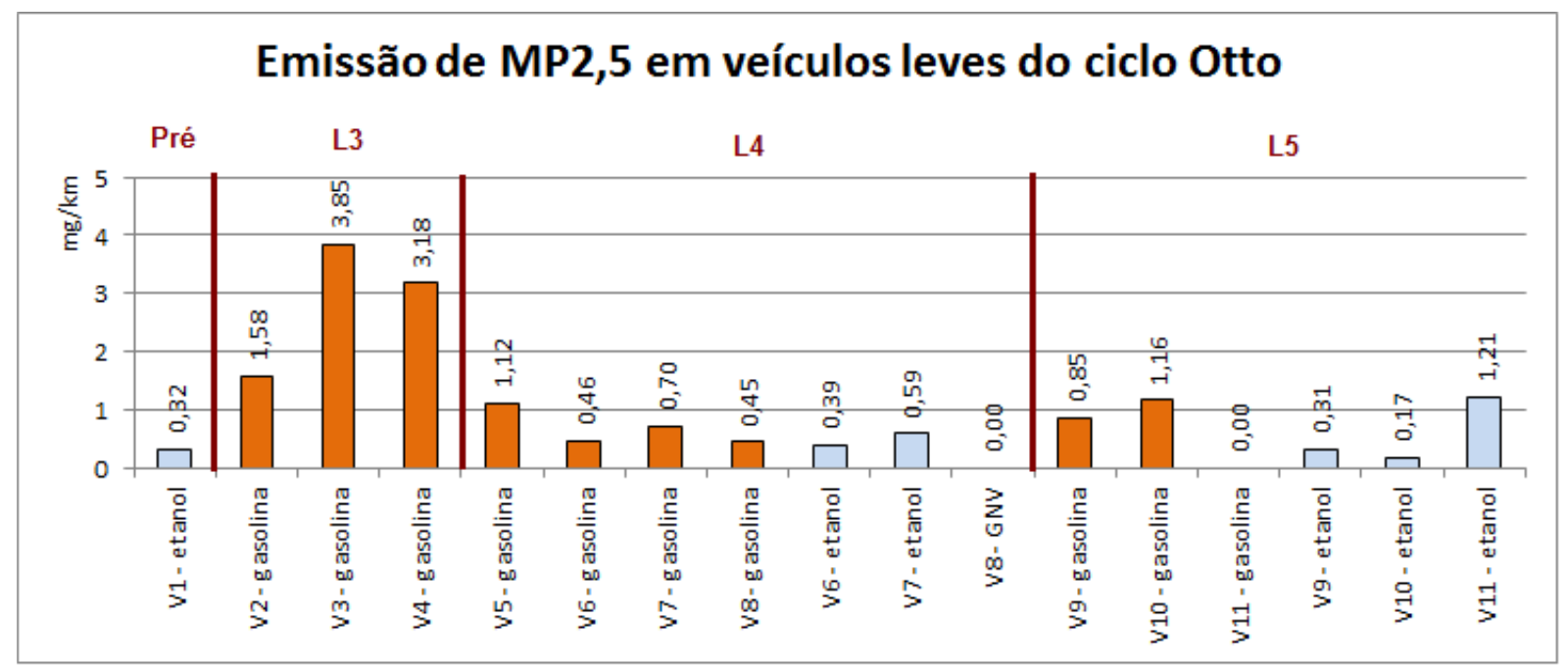

Figura 5: Fatores de emissão para veículos do ciclo Otto, com gasolina C, etanol e GNV.

As motocicletas (Figura 6) apresentaram um nível de emissão de MP mais elevado que os veículos, sem tendência clara de variação que possa ser associada à evolução do PROMOT. O valor médio da emissão de MP foi de $6,04 \mathrm{mg} / \mathrm{km}$ para os ensaios efetuados com gasolina $\mathrm{C}$ e $3,32 \mathrm{mg} / \mathrm{km}$ no único teste com etanol. A título de comparação, no inventário de emissões rodoviárias do MMA utilizou-se um fator de $14 \mathrm{mg} / \mathrm{km}$ para motocicletas da fase M1 rodando com gasolina e 3,5 mg/km para as das fases M2 e M3. 


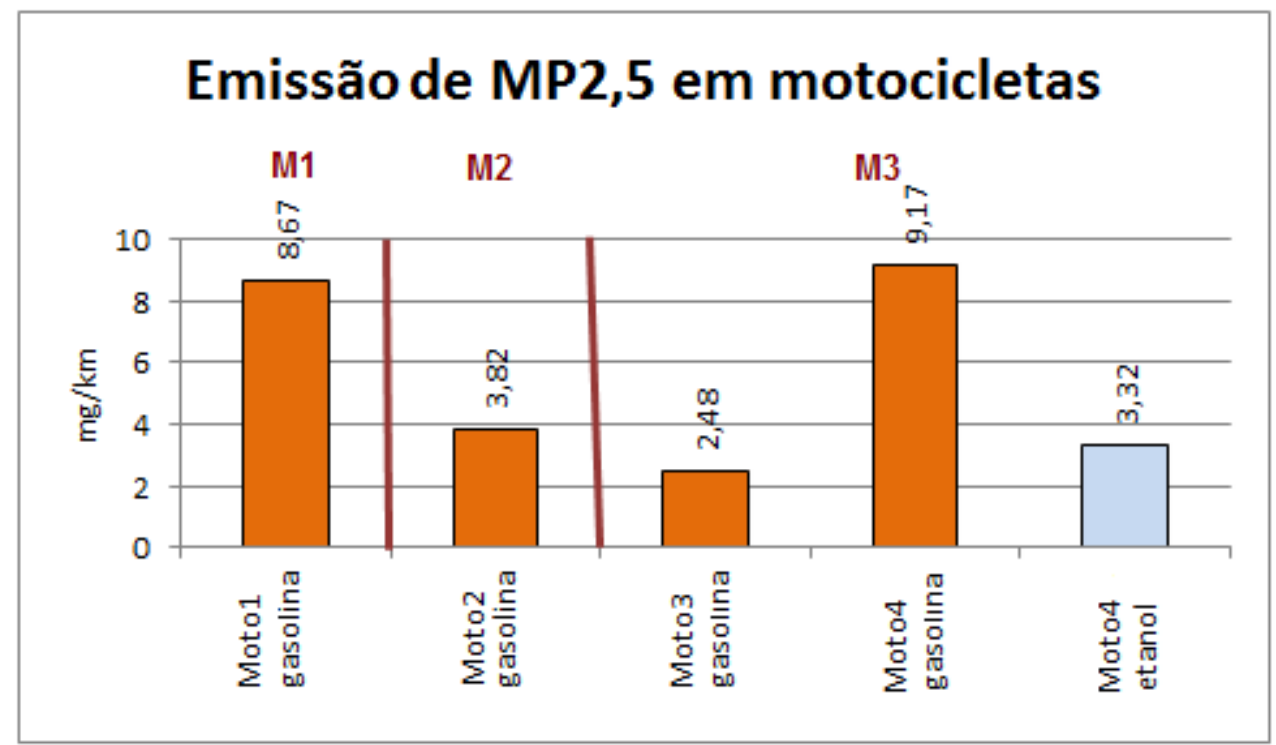

Figura 6: Fatores de emissão para motocicletas, com gasolina C e etanol.

Como esperado, o nível de emissão de MP nos veículos leves a diesel (Figura 7) é bastante superior aos dos veículos e motocicletas do ciclo Otto. Salienta-se que, apesar de alguns deles possuírem quilometragem superior a $80.000 \mathrm{~km}$, todos ainda estavam abaixo dos respectivos limites do PROCONVE. Para os veículos de fases anteriores (L3 e L4) não se evidenciou uma diminuição da emissão de MP decorrente da redução do teor de enxofre do combustível, enquanto no veículo mais recente (L6) isto foi perceptível. Já nos motores pesados a diesel (Figura 8) essa influência é percebida quando se reduziu o teor de enxofre do óleo diesel para um valor abaixo de 500 ppm, porém não foi evidenciada entre os teores de 50 e 10 ppm.

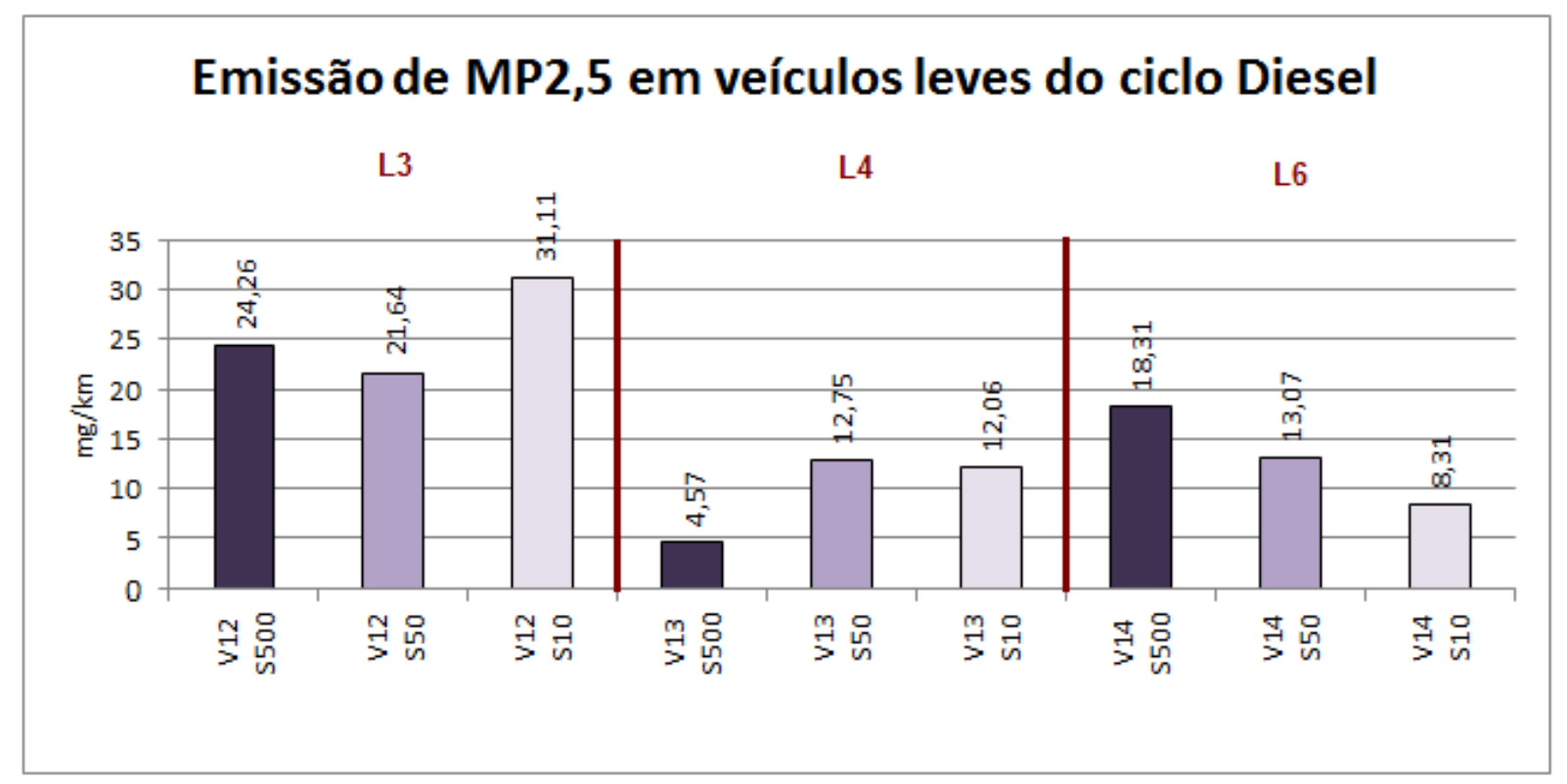

Figura 7: Fatores de emissão para veículos leves do ciclo Diesel com S500, S50 e S10. 


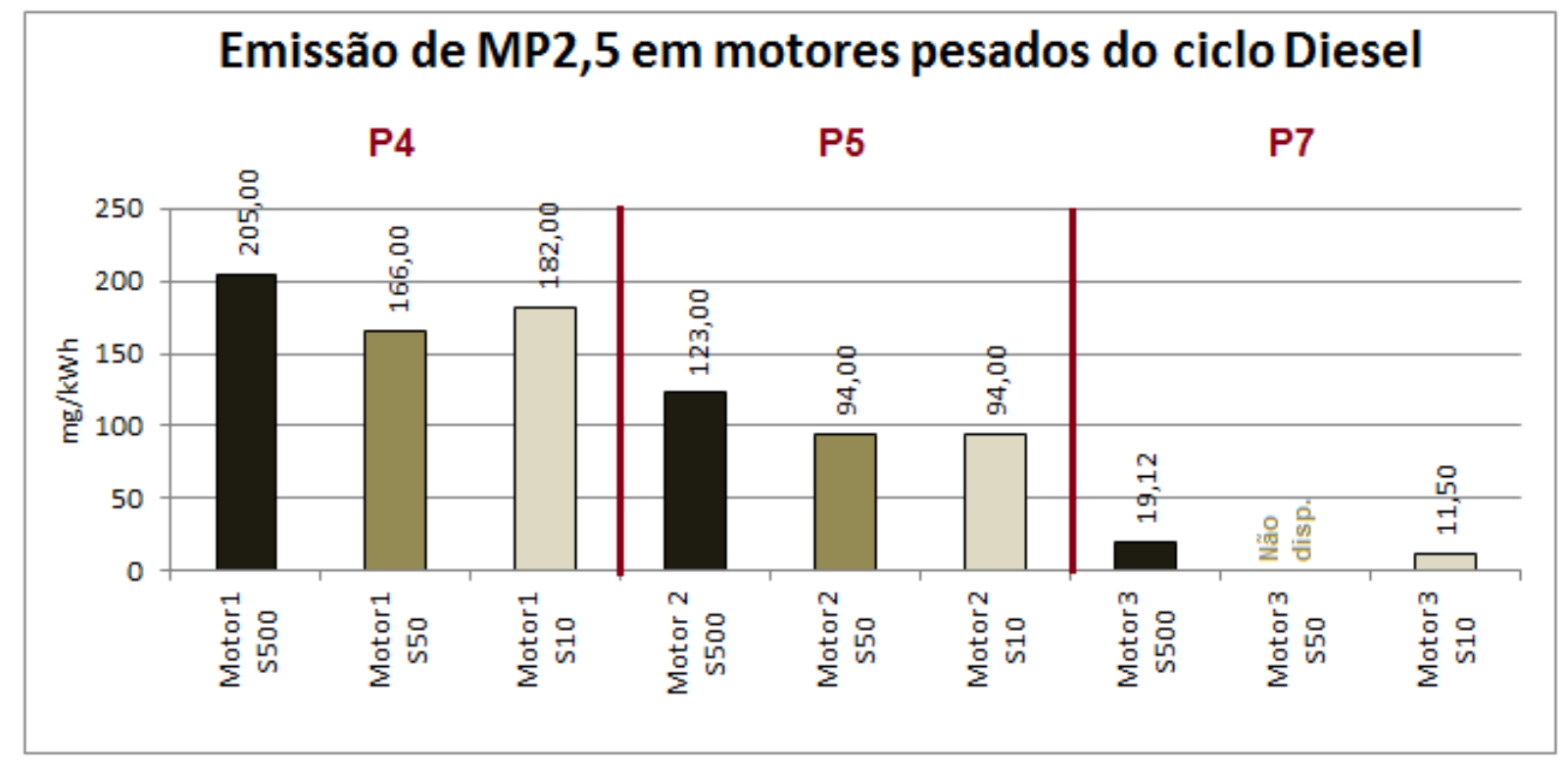

Figura 8: Fatores de emissão para motores pesados a diesel com S500, S50 e S10.

\subsection{CONCENTRAÇÕES MÉDIAS DE MP}

As Figuras 9 e 10 representam a concentração média no período de amostragem para o material particulado fino $\left(\mathrm{MP}_{2.5}\right)$, grosso $\left(\mathrm{MP}_{2,5-10}\right)$ e do $\mathrm{MP}_{10}$ no Rio de Janeiro e em São Paulo.

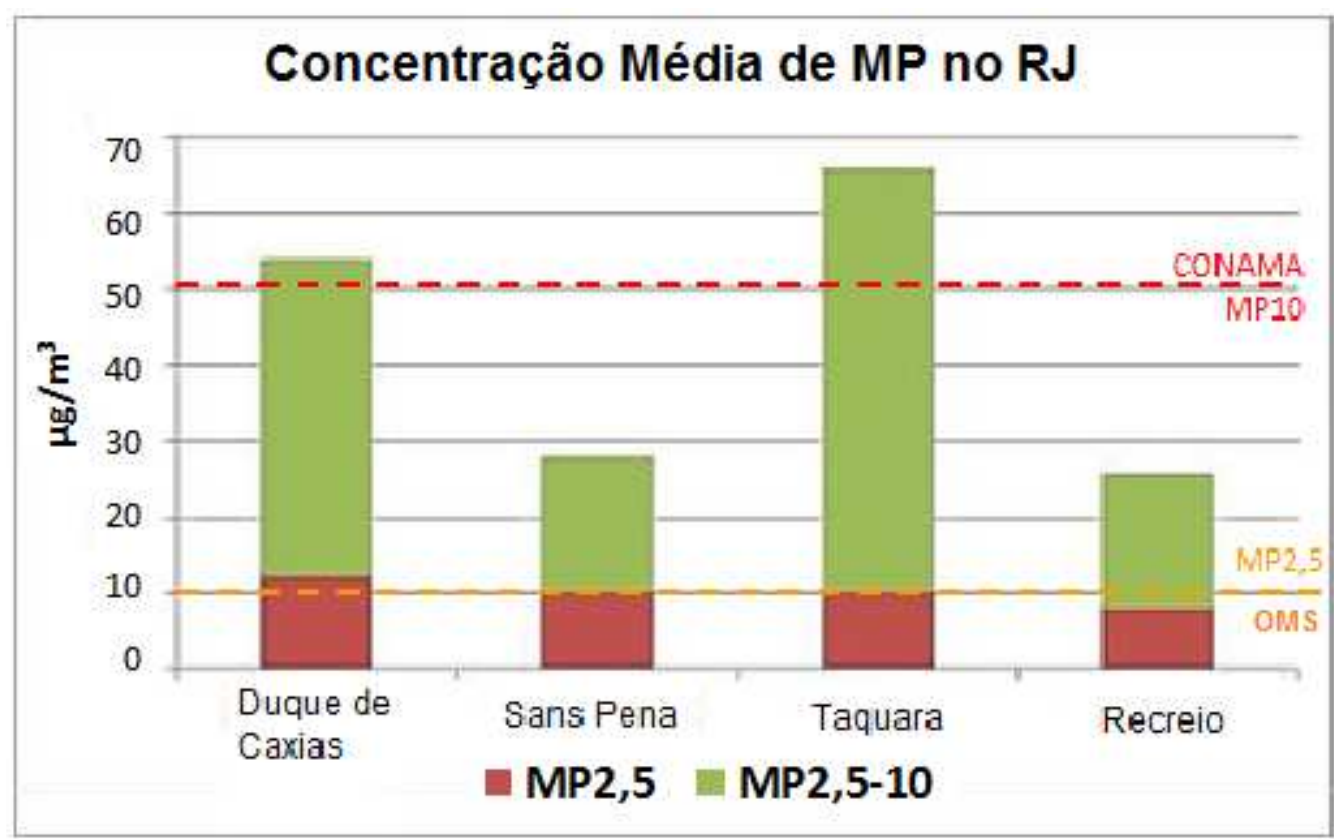

Figura 9: Média anual da concentração mássica no particulado fino, grosso e $\mathrm{MP}_{10}$ no Rio de Janeiro 


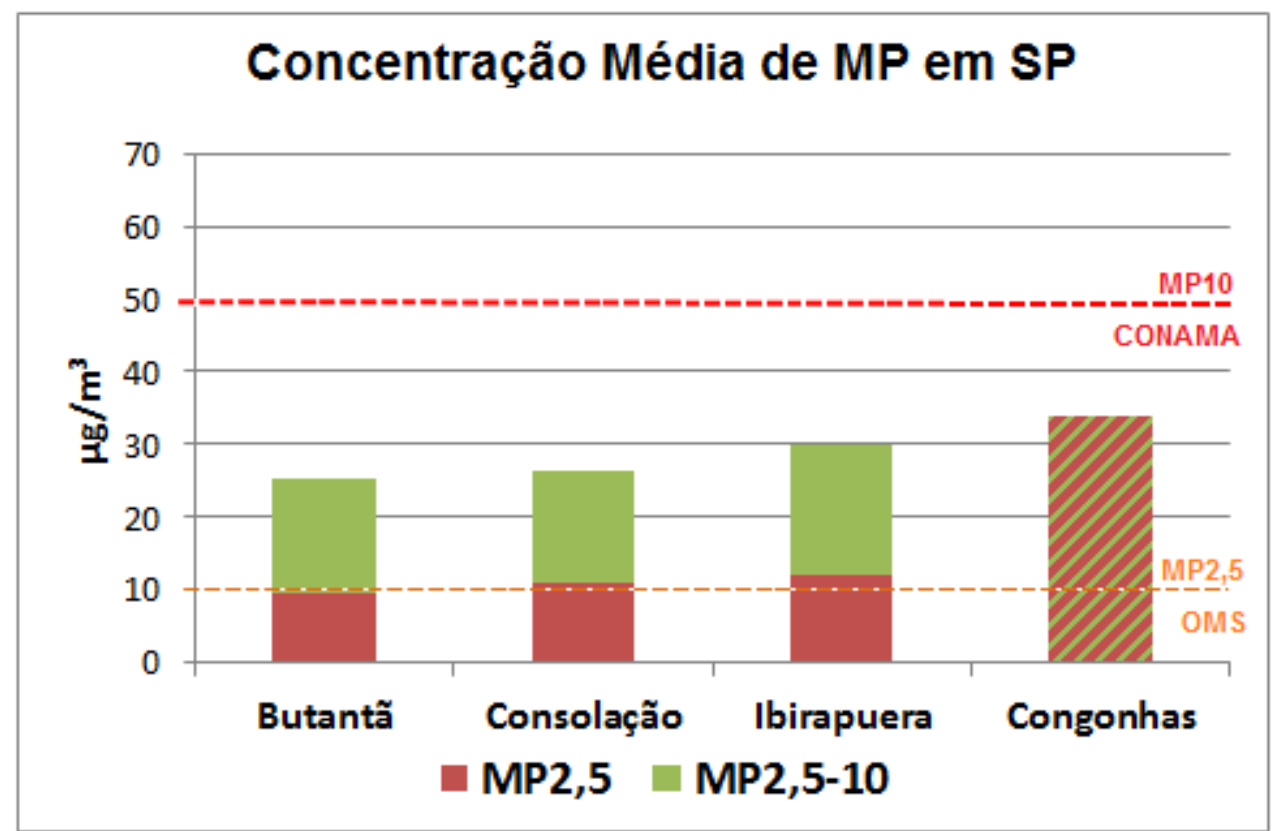

Nota: Em Congonhas não foi possivel separar as duas modas

Figura 10: Média anual da concentração mássica no particulado fino, grosso e $\mathrm{MP}_{10}$ em São Paulo.

Nota-se que a concentração do particulado fino é muito semelhante entre todos os pontos de monitoramento nas duas regiões metropolitanas, variando em torno de $10 \mu \mathrm{g} . \mathrm{m}^{-3}$, que vem a ser o limite máximo recomendado pela OMS [12]. Conclui-se que, apesar da distância entre as duas regiões e das estações entre si, além das diferentes características locais, o processo de mistura nessas metrópoles é bastante efetivo na homogeneização do poluente. Isso é corroborado por medições semelhantes realizadas dez anos antes no Rio de Janeiro [13]. Interessante notar que, apesar do aumento do tráfego veicular na região do Recreio dos Bandeirantes, os resultados obtidos no presente estudo são, exatamente, os mesmos obtidos uma década antes [13], indicando que este aumento foi compensado pela renovação tecnológica da frota e melhoria na qualidade do combustível nacional.

Com relação ao particulado grosso, percebe-se novamente semelhança entre as concentrações das duas metrópoles. No entanto, verificou-se também que essa fração é fortemente influenciada pelas condições locais. Observou-se no Rio de Janeiro que as obras de infraestrutura em andamento próximo às estações Taquara (construção do sistema BRT) e Duque de Caxias (construção do Anel Rodoviário) tiveram forte impacto nesta fração, fazendo que o limite anual para $\mathrm{MP}_{10}$ prescrito na Resolução CONAMA 03 de 1990 (50 $\mu \mathrm{g} \cdot \mathrm{m}^{-3}$ ) fosse ultrapassado em ambas as estações.

\subsection{PARTICIPAÇÃO DAS FONTES NO MP 2,5}

O processo de identificação das fontes que contribuem para o material particulado começou com uma etapa de triagem das variáveis a serem consideradas, na qual foram descartadas aquelas com muitos valores abaixo ou próximos ao limite de quantificação. $\mathrm{O}$ processo continuou com a seleção das variáveis que apresentaram correlação entre si. Ao final destas etapas, conseguiu-se obter um conjunto de variáveis explicativas (fontes emissoras) semelhantes nas estações. 
O método da Análise dos Componentes Principais (ACP) empregado visou estabelecer as relações entre parâmetros e fatores que compõem o material particulado. A Tabela 3 exemplifica o resultado da aplicação do método no particulado fino da Estação Duque de Caxias. Nela se apresenta os "factor loadings" para cada parâmetro incluído na base de dados. A associação mais forte entre estes parâmetros, ressaltada em amarelo, indica a que fonte ele se refere como, por exemplo, aos elementos crustais (terras raras, $\mathrm{Al} \mathrm{e} \mathrm{Fe}$ ), indicando que o fator 1, que compõe o material particulado fino neste ponto, trata-se de solo ou de sulfato e amônia. $\mathrm{O}$ fator 2, por sua composição é indicado como particulado secundário.

Tabela 3: Aplicação da Análise por Componentes Principais para particulado fino na Estação Duque de Caxias, apresentando a matriz com os "factor loading" e as fontes identificadas.

\begin{tabular}{|c|c|c|c|c|c|c|c|}
\hline Elemento & $\begin{array}{c}\text { Fator } 1 \\
\text { Solo }\end{array}$ & $\begin{array}{c}\text { Fator } 2 \\
\text { Aerossol sec. e } \\
\text { queima de óleo }\end{array}$ & $\begin{array}{c}\text { Fator } 3 \\
\text { Tráfico } \\
\text { veicular }\end{array}$ & $\begin{array}{c}\text { Fator } 4 \\
\text { Queima de } \\
\text { biomassa }\end{array}$ & $\begin{array}{c}\text { Fator } 5 \\
\text { Spray } \\
\text { marinho }\end{array}$ & $\begin{array}{c}\text { Fator } 6 \\
\text { Indústria }\end{array}$ & Comunalidade \\
\hline $\begin{array}{c}\mathrm{Th} \\
\mathrm{Ti} \\
\mathrm{Ce} \\
\mathrm{Nd} \\
\mathrm{Sm} \\
\mathrm{U} \\
\mathrm{Ca} \\
\mathrm{Al} \\
\mathrm{Fe} \\
\text { amônia } \\
\text { sulfato } \\
\mathrm{V} \\
\mathrm{As} \\
\mathrm{Ni} \\
\mathrm{MPF} \\
\mathrm{Ba} \\
\mathrm{BC} \\
\mathrm{Mn} \\
\mathrm{OC} \\
\mathrm{K} \\
\mathrm{Rb} \\
\mathrm{Cd} \\
\mathrm{EC} \\
\mathrm{Na} \\
\mathrm{Ma} \\
\text { nitrato } \\
\mathrm{Pb} \\
\mathrm{Cu} \\
\text { cloreto } \\
\mathrm{Zn}\end{array}$ & $\begin{array}{l}.947 \\
.943 \\
.935 \\
.933 \\
.932 \\
.900 \\
.800 \\
.739 \\
.650 \\
-.141 \\
-.166 \\
\\
.151 \\
.134 \\
.330 \\
.218 \\
.442 \\
.504 \\
.442 \\
.511 \\
.368 \\
.293 \\
\\
.436 \\
.135\end{array}$ & $\begin{array}{l}.268 \\
.894 \\
.884 \\
.834 \\
.776 \\
.730 \\
.657 \\
.191 \\
.158 \\
.156 \\
.240 \\
.214 \\
.222 \\
-.294 \\
.117 \\
.175 \\
.275 \\
.156 \\
-.220 \\
.285 \\
\end{array}$ & $\begin{array}{l}.094 \\
.188 \\
.185 \\
.183 \\
.299 \\
.572 \\
. .092 \\
\\
.185 \\
.280 \\
.184 \\
.852 \\
.795 \\
.626\end{array}$ & $\begin{array}{l}.123 \\
.153 \\
.218 \\
.233 \\
.283 \\
.187 \\
.189 \\
.160 \\
.125 \\
.104 \\
.481 \\
. .124 \\
.325 \\
.749 \\
.665 \\
.645 \\
.475 \\
.442 \\
.092 \\
.395\end{array}$ & $\begin{array}{r}-.109 \\
.375 \\
.342 \\
.124 \\
-.440 \\
.896 \\
.764 \\
.623\end{array}$ & $\begin{array}{l}.105 \\
.121 \\
\\
.193 \\
.094 \\
.196 \\
.111 \\
.118 \\
.279\end{array}$ & $\begin{array}{l}.919 \\
.923 \\
.940 \\
.956 \\
.958 \\
.842 \\
.833 \\
.590 \\
.875 \\
.870 \\
.866 \\
.791 \\
.673 \\
.647 \\
.907 \\
.806 \\
.792 \\
.690 \\
.858 \\
.838 \\
.852 \\
.595 \\
.753 \\
.821 \\
.847 \\
.636 \\
.817 \\
.689 \\
.650 \\
.414 \\
\end{array}$ \\
\hline Autovalor & 8.5 & 4.5 & 2.8 & 2.7 & 2.6 & 2.5 & Variância total \\
\hline Variância & 28.2 & 15.1 & 9.4 & 9.1 & 8.7 & 8.4 & 78.8 \\
\hline
\end{tabular}

De modo a validar esta avaliação, aplicou-se outra ferramenta estatística, chamada Análise por Agrupamentos (Cluster Analysis), na qual a menor distância entre os parâmetros indica a sua associação e, consequentemente, a sua origem comum.

Uma vez identificadas as fontes presentes em cada local de amostragem e que compõem o material particulado, a etapa seguinte consistiu na determinação da fração da massa do material particulado correspondente a cada uma delas. Para tal, empregou-se o método da Análise de Componentes Principais Absoluta (ACPA). 
Quando da aplicação de modelos estatísticos, um dos desafios que se impõe é a validação dos resultados obtidos. No caso da aplicação da ACPA, para fins de quantificação das fontes que compõem o material particulado, uma das formas de fazê-lo é recompor a composição química de cada componente identificado e compará-la ao perfil esperado para este tipo de fonte. Como perfil esperado, utilizou-se, no caso do componente tráfego veicular, os resultados obtidos das análises do MP coletado dos veículos e motores ensaiados, e nos demais casos, perfis típicos retirados do banco de dados EPA-Speciate [14].

Na Figura 11 está ilustrado o resultado obtido para os perfis identificados como "tráfego veicular" nas estações utilizando a ACPA e os resultados medidos em laboratório. Ressalta-se que o perfil médio das emissões coletadas nos ensaios veiculares foi composto ponderando-se os resultados obtidos com cada veículo e combustível com a composição média da frota por fase do PROCONVE/PROMOT, segundo o $2^{\circ}$ Inventário Nacional de Emissões Rodoviárias [11]. Pode-se notar, em todos os casos, uma concordância bastante grande entre os perfis.

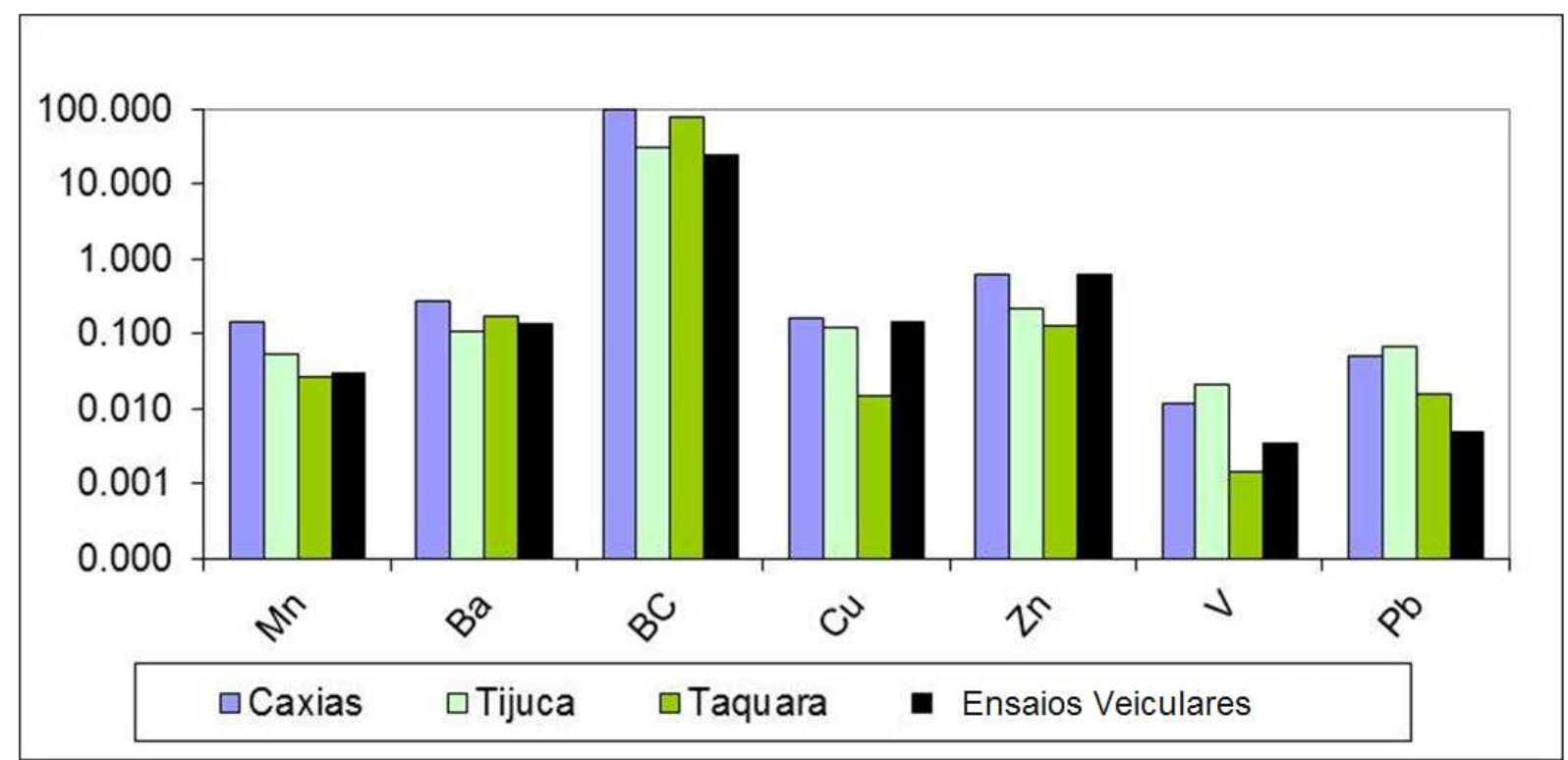

Figura 11: Perfil reconstituído da fonte Tráfego Veicular no material particulado fino em 3 estações do Rio de Janeiro, comparado com o perfil obtido dos ensaios veiculares.

Como a validação das fontes identificadas utilizando a ACPA, procedeu-se o cálculo da participação das mesmas no MP ambiental coletado. Ressalta-se que nesta fase, não foi possível distinguir entre a participação das emissões diretas de veículos do ciclo Otto e do ciclo Diesel, que apareceram então dentro de um único fator.

Os resultados para o material particulado fino no Rio de Janeiro são apresentados na Tabela 4 e na Figura 12. Nelas verifica-se que a maior contribuição média é oriunda das fontes veiculares $(34 \%)$, seguida pelo aerossol secundário (25\%), solo (17\%), queima de biomassa $(12 \%)$, aerossol marinho (11\%) e indústria (2\%).

Particularmente para as fontes veiculares, observou-se uma variabilidade acentuada, com uma participação que vai de $19 \%$ em Duque de Caxias a 57\% na Tijuca. Já para os aerossóis secundários, a maior parte dos quais pode ser atribuída à reação de COVs de origem veicular, a variação foi bem menor, indo de 13\% (Tijuca) a 36\% (Recreio). 
Tabela 4: Percentual da massa de MP2,5 atribuída às diferentes fontes no Rio de Janeiro

\begin{tabular}{|l|c|c|c|c|c|c|}
\hline Estações & Veículos & $\begin{array}{c}\text { Aerossol } \\
\text { Secundário }\end{array}$ & Indústria & $\begin{array}{c}\text { Aerossol } \\
\text { Marinho }\end{array}$ & Solo & $\begin{array}{c}\text { Queima } \\
\text { Biomassa }\end{array}$ \\
\hline Caxias & $19 \%$ & $29 \%$ & $6 \%$ & $12 \%$ & $19 \%$ & $15 \%$ \\
\hline Tijuca & $57 \%$ & $13 \%$ & - & $10 \%$ & $20 \%$ & - \\
\hline Taquara & $36 \%$ & $22 \%$ & $1 \%$ & $8 \%$ & $14 \%$ & $19 \%$ \\
\hline Recreio & $23 \%$ & $36 \%$ & - & $14 \%$ & $15 \%$ & $12 \%$ \\
\hline Média & $\mathbf{3 4 \%}$ & $\mathbf{2 5 \%}$ & $\mathbf{2 \%}$ & $\mathbf{1 1 \%}$ & $\mathbf{1 7 \%}$ & $\mathbf{1 2 \%}$ \\
\hline
\end{tabular}

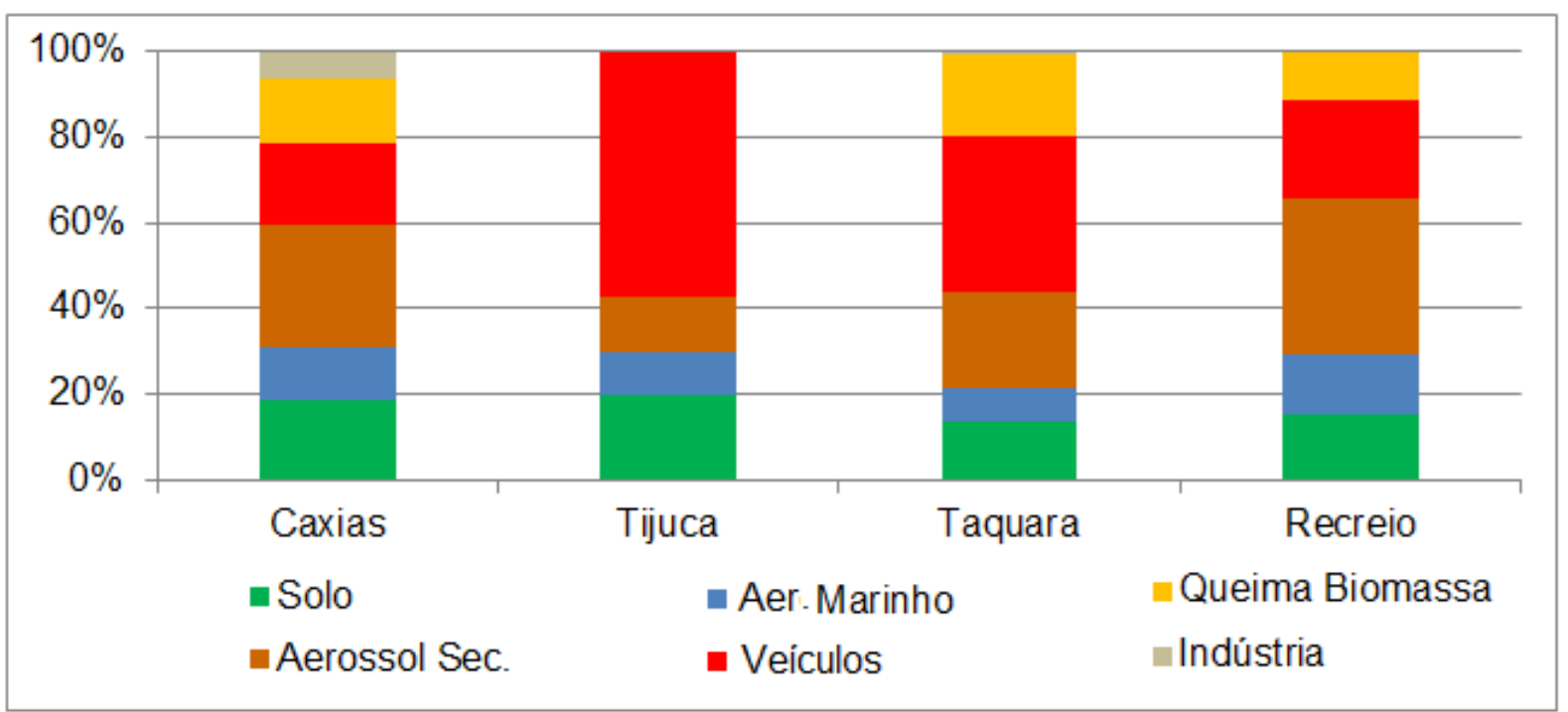

Figura 12: Composição no MP fino atribuída as diferentes fontes no Rio de Janeiro.

A participação das fontes no material particulado fino coletado em 3 estações de São Paulo é apresentada na Tabela 5 e na Figura 13. Na estação de Congonhas não foi possível efetuar a separação, tendo em vista que a maior parte dos filtros entupiu muito rapidamente devido à excessiva proximidade da estação com vias de tráfego pesado.

Como pode ser observado, em São Paulo a maior participação no $\mathrm{MP}_{2,5}$ também é atribuída à emissão direta por veículos, com $48 \%$ em média, com variação bem menor que no Rio de Janeiro. Por ordem de importância seguem-se a indústria (20\%), o aerossol secundário (15\%), solo $(12 \%)$ e o aerossol marinho $(5 \%)$.

Tabela 5: Percentual da massa do particulado fino atribuída às diferentes fontes em São Paulo.

\begin{tabular}{|l|c|c|c|c|c|}
\hline \multicolumn{1}{|c|}{ Estações } & Veículos & $\begin{array}{c}\text { Aerossol } \\
\text { Secundário }\end{array}$ & Indústria & $\begin{array}{c}\text { Aerossol } \\
\text { Marinho }\end{array}$ & Solo \\
\hline Consolação & $42 \%$ & $15 \%$ & $23 \%$ & $6 \%$ & $14 \%$ \\
\hline Butantã & $52 \%$ & 18 & $18 \%$ & $5 \%$ & $7 \%$ \\
\hline Ibirapuera & $50 \%$ & $13 \%$ & $18 \%$ & $4 \%$ & $15 \%$ \\
\hline Média & $\mathbf{4 8 \%}$ & $\mathbf{1 5 \%}$ & $\mathbf{2 0 \%}$ & $\mathbf{5 \%}$ & $\mathbf{1 2 \%}$ \\
\hline
\end{tabular}




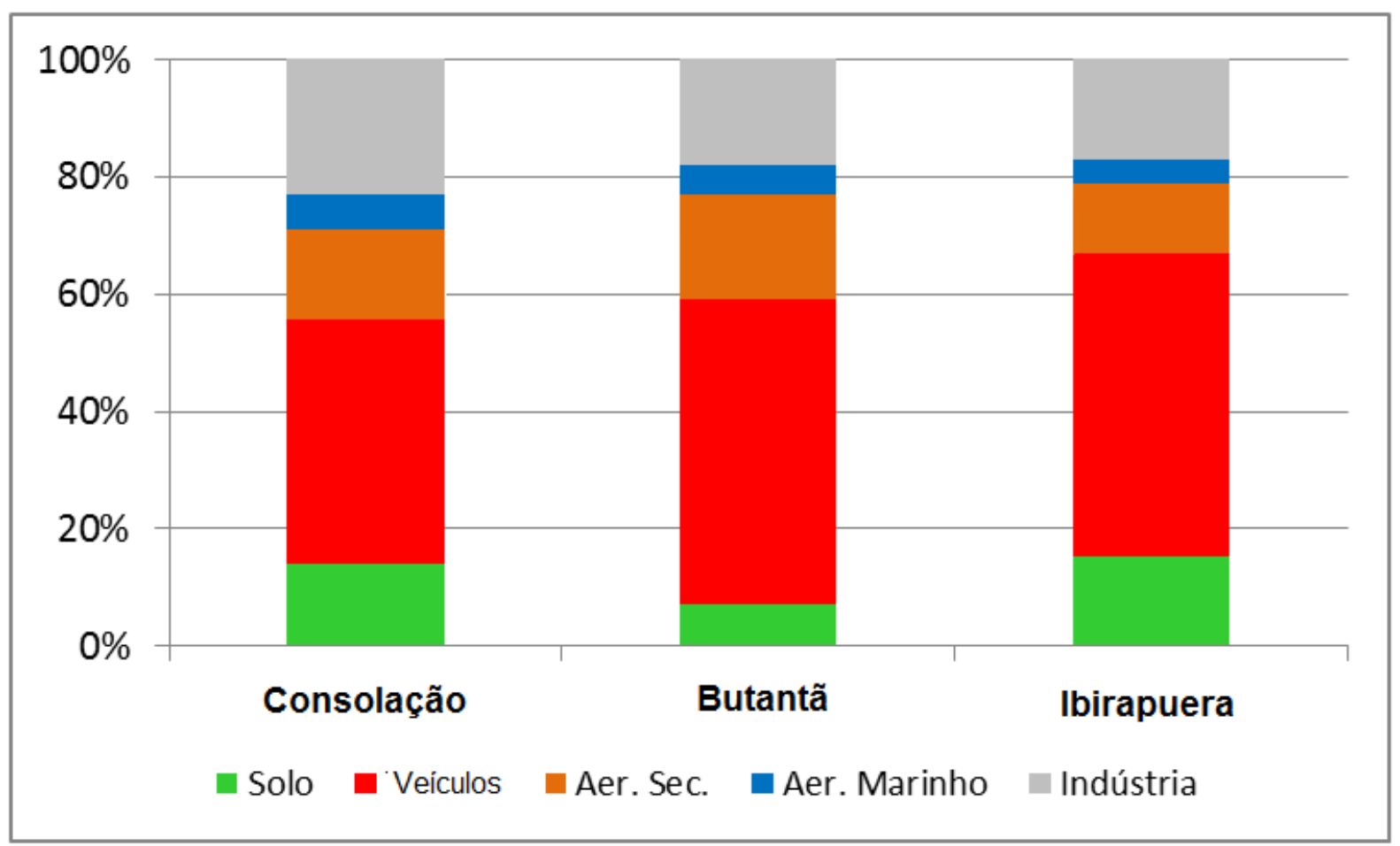

Figura 13: Composição no MP fino atribuída as diferentes fontes em São Paulo.

Na comparação entre os resultados das duas metrópoles, verifica-se que, se por um lado em São Paulo a contribuição direta das fontes veiculares é maior que no Rio de Janeiro, por outro na metrópole paulista a influência dos aerossóis secundários é menor. Entretanto, analisando a participação conjunta das fontes veiculares e dos aerossóis secundários, observa-se que no Rio de Janeiro e em São Paulo ela é bastante semelhante: em média 59\% e 63\%, respectivamente.

\subsection{PARTICIPAÇÃO DAS FONTES NO MP 1}

Durante um período de cerca de 3 meses foi feita a amostragem em tempo real de aerossóis e gases na Consolação (SP) e na Taquara (RJ), estações essas próximas a importantes fontes de emissão veiculares. Nelas mediu-se a composição química não-refratária menor que $1 \mu \mathrm{m}$, utilizando o AMS, a concentração de black carbon, com o MAAP, a distribuição de tamanho de partículas manométricas, pelo SMPS, além da concentração de uma gama de compostos orgânicos voláteis, através do PTR-MS. Com isso pretendia-se separar a influência dos veículos do ciclo Diesel e do ciclo Otto na formação do MP atmosférico, já que a análise dos filtros não o permitiu.

Ao aplicar a técnica Análise de Fatores Principais Positivada às medições em tempo real, pôde-se identificar 3 fatores primordialmente ligados a emissões veiculares: um relativo a emissões primárias de veículos diesel, outros para veículos a gasolina e/ou etanol, assim como um terceiro, proveniente de reações secundárias de COV na atmosfera. Um quarto fator foi atribuído a sulfato de origem industrial e amônia.

A participação das principais fontes de $\mathrm{MP}_{1}$ ambiental para São Paulo e Rio de Janeiro pode ser observada nas Figuras 14 e 15. 


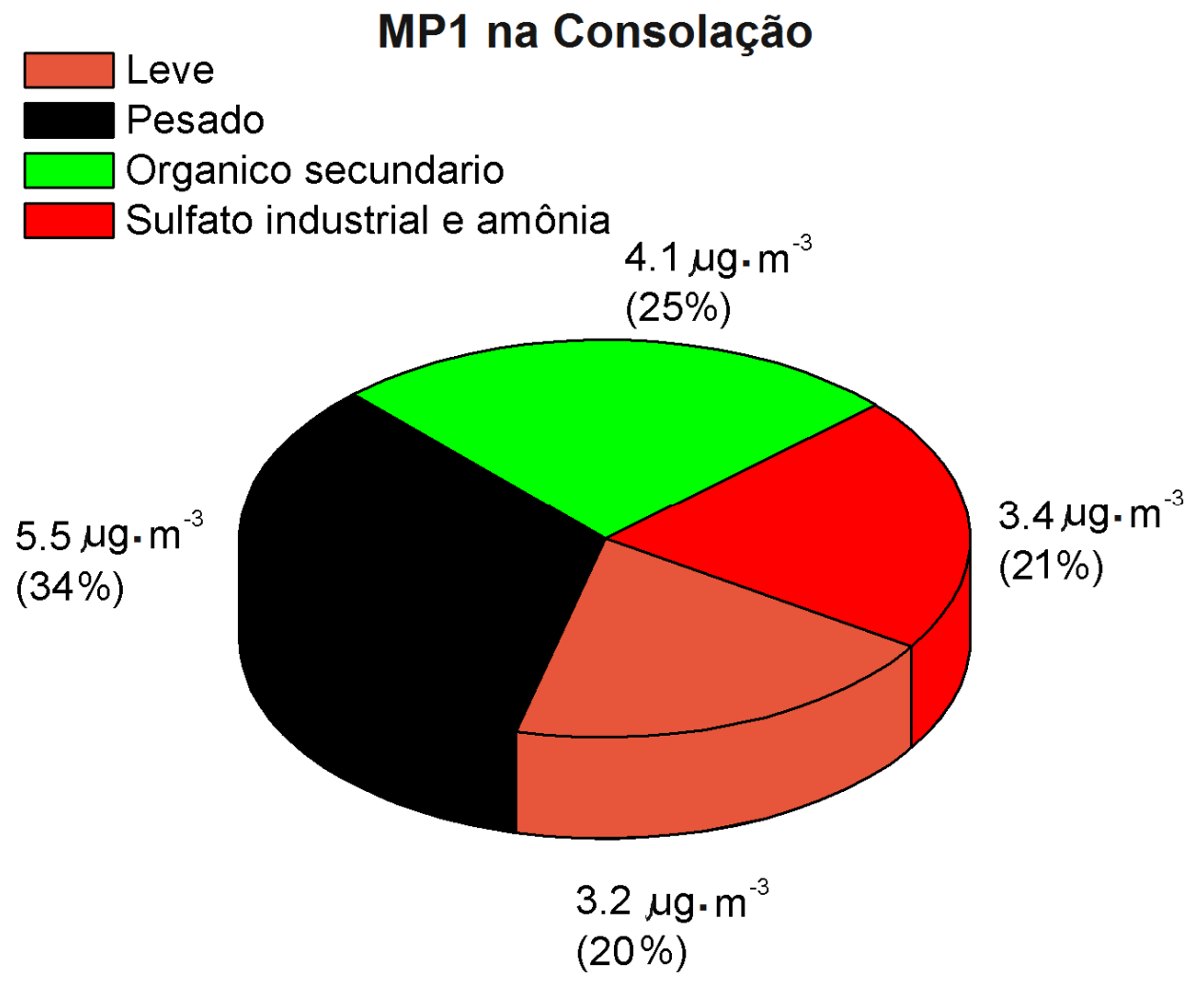

Figura 14: Contribuição por fonte na estação da Consolação (SP) identificado por instrumentação de tempo real.

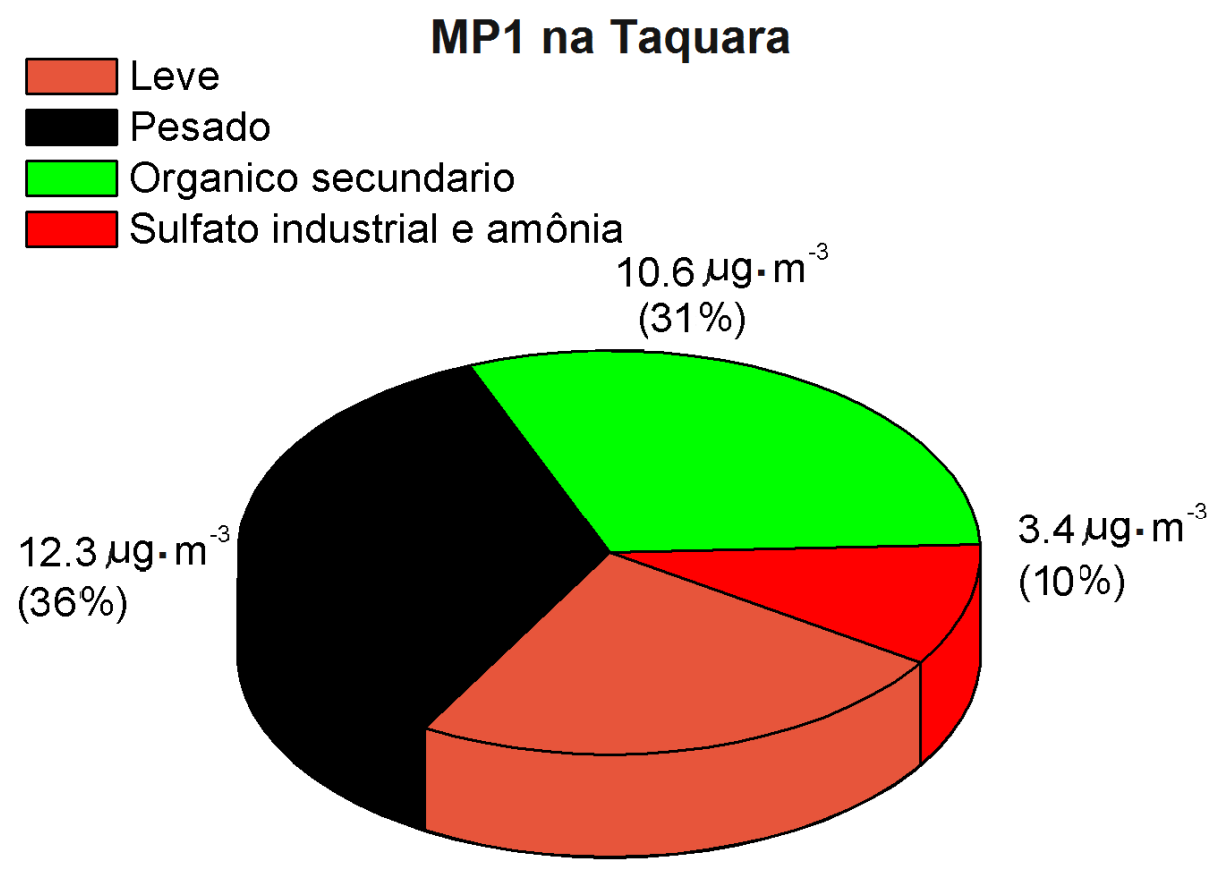

$8.4 \mu \mathrm{g} \cdot \mathrm{m}^{-3}$
$(24 \%)$

Figura 15: Contribuição por fonte na estação da Taquara (RJ) identificado por instrumentação de tempo real. 
Foi identificado que emissão direta de veículos do ciclo Otto e do Diesel são responsáveis respectivamente por $20 \%$ e $34 \%$ do $\mathrm{MP}_{1}$ medido na Consolação, enquanto o aerossol orgânico secundário representa $25 \%$ do total naquela estação. De forma muito semelhante, observou-se que na Taquara (RJ) a participação dessas fontes corresponde a $24 \%, 36 \%$ e $31 \%$. Interessante notar que a fração associada com emissão direta de $\mathrm{MP}_{1}$ por veículos (Diesel+Otto) na Taquara $(60 \%)$ e na Consolação $(53 \%)$ foi bastante próxima, mesmo sendo a concentração média na estação paulista três vezes menor que na carioca.

\section{CONCLUSÃO}

Esse trabalho faz parte de um conjunto de ações de iniciativa da Petrobras que beneficiam a ampliação do conhecimento da influência de seus produtos disponibilizados para a sociedade. Além disso, apresenta uma contribuição importante para o desenvolvimento da área analítica, pela adoção de novas ferramentas e técnicas de atribuição de fontes em poluentes atmosféricos, permitindo conectar a evolução de motores e combustíveis ao progresso de mecanismos de quantificação da participação relativa das emissões veiculares.

Nas medições realizadas em laboratório, foram encontrados fatores de emissão e composições para o MP oriundo da combustão de gasolina e de diesel compatíveis com outros trabalhos. Destaca-se a inédita obtenção de fatores de emissão de MP para veículos e motocicletas com etanol. Não foi possível diferenciar assinaturas de MP distintas para gasolina e etanol.

Os resultados obtidos na amostragem ambiental mostraram que, apesar do aumento da frota ocorrido nos últimos anos no Rio de Janeiro e em São Paulo, a qualidade do ar em termos da concentração de MP não sofreu alteração importante. Tal fato pode ser creditado à evolução tecnológica e renovação da frota, assim como a melhoria nos combustíveis nacionais. Foi possível constatar que, a atmosfera na região metropolitana das duas cidades é muito homogênea com a concentração de material particulado fino na faixa de $8-12 \mu \mathrm{g} \mathrm{m} \mathrm{m}^{-3}$, resultado esse próximo ao valor recomendado pela OMS.

Observou-se que o material particulado grosso possui um caráter mais local, sendo que as obras públicas existentes na região das estações da Taquara e Duque de Caxias contribuíram para que a média anual do $\mathrm{MP}_{10}$ ultrapassasse o limite da Resolução CONAMA 03/90. Nas demais estações, a concentração desta fração do MP atendeu ao referido limite.

Verificou-se, também, que a contribuição da emissão veicular direta para a massa do particulado fino variou entre um mínimo de $19 \%$ e um máximo de $57 \%$ nas estações, com um valor médio de $34 \%$ no Rio de Janeiro e $48 \%$ em São Paulo. Já para os aerossóis secundários, a maior parte dos quais pode ser atribuído a reações das quais participam compostos orgânicos voláteis de origem veicular, a contribuição foi de $25 \%$ no Rio de Janeiro e $15 \%$ em São Paulo. Considerando os dois tipos de fontes, a participação média foi de $59 \%$ na primeira metrópole e $63 \%$ na segunda, ou seja, bastante semelhantes entre si.

Se para o $\mathrm{MP}_{2,5}$ não foi possível separar a contribuição dos veículos a diesel daqueles com motores do ciclo Otto, a utilização de equipamentos de medição em tempo real para o material particulado ultrafino tornou isso viável. Em São Paulo e no Rio de Janeiro a 
contribuição média dos motores diesel e Otto para o $\mathrm{MP}_{1}$ foram de $35 \%$ e $22 \%$, respectivamente, enquanto a dos aerossóis secundários,foi de $28 \%$.

Devido a importância relativa dos aerossóis secundários no MP atamosférico, sugere-se aprofundar estudos sobre a especiação dos compostos orgânicos voláteis no gás de escapamento veicular, assim como sobre os mecanismos de cinética química em que eles participam na atmosfera.

\section{AGRADECIMENTOS}

Ao Instituto de Energia e Meio Ambiente (IEMA), entidade sem fins lucrativos que coopera para a promoção do desenvolvimento sustentável, por seu auxílio no processo de seleção dos veículos representativos da frota circulante para os ensaios veiculares.

Ao Instituto de Tecnologia para o Desenvolvimento (Lactec), em cujo laboratório de emissões foram testados diversos veículos leves e motocicletas, além de um motor pesado a diesel.

Às instituições participantes do projeto: o Departamento de Química e ao Centro Técnicocientífico da PUC-RIO, o Instituto de Radioproteção e Dosimetria (IRD-CNEN), o Instituto de Física (IF-USP) e o Instituto de Astronomia, Geofísica e Ciências Atmosféricas (IAGUSP) da Universidade de São Paulo.

A viabilização do monitoramento ambiental foi também fruto da colaboração das agências ambientais Companhia de Tecnologia de Saneamento Ambiental do Estado de São Paulo (CETESB), Instituto Estadual do Ambiente do Estado do Rio de Janeiro (INEA) e Secretaria Municipal de Meio Ambiente do Município do Rio deJaneiro (SMAC) que gentilmente cederam espaço físico em suas estações de monitoramento ambiental para a instalação dos equipamentos de coleta e análise de material particulado atmosférico.

\section{REFERÊNCIAS}

[1] ABNT - ASSOCIAÇÃO BRASILEIRA DE NORMAS TÉCNICAS, NBR 6601 Determinação de Hidrocarbonetos, Monóxido de Carbono, Óxidos de Nitrogênio e Dióxido de Carbono no Gás de Escapamento, Brasil, 2012.

[2] Parlamento Europeu, Diretiva 97/24/CE, 1997.

[3] ABNT - ASSOCIAÇÃO BRASILEIRA DE NORMAS TÉCNICAS, NBR 14.489 Motor diesel - Análise e determinação dos gases e do material particulado emitidos por motores do ciclo diesel - Ciclo de 13 pontos,Brasil, 2000.

[4] ABNT - ASSOCIAÇÃO BRASILEIRA DE NORMAS TÉCNICAS, NBR 15634 Veículos rodoviários automotores - Análise e determinação do gás de exaustão segundo os ciclos ETC, ESC e ELR, Brasil, 2010.

[5] http://www.panalytical.com/Epsilon-5.htm, acesso em 28/05/2015.

[6] BIRCH, M.E., CARY R.A., Elemental Carbon-Based Method for Monitoring Occupational Exposures to Particulate Diesel Exhaust, Aerosol Science and Technology 25, 221-241, 1996

[7] http://www.aerodyne.com/products/aerosol-mass-spectrometer, acesso em 28/05/2015. 
[8] http://www.thermoscientific.com/en/product/5012-multiangle-absorption-photometermaap.html, acesso em 28/05/2015.

[9] http://www.tsi.com/scanning-mobility-particle-sizer-spectrometer-3936, acesso em 28/05/2015.

[10] http://www.ionicon.com/information/technology/ptr-ms, acesso em 28/05/2015.

[11] MINISTÉRIO DO MEIO AMBIENTE, Inventário Nacional de Emissões Atmosféricas por Veículos Automotores Rodoviários - 2013, Brasília, 2014.

[12] WORLD HEALTH ORGANIZATION, WHO Air quality guidelines for particulate matter, ozone, nitrogen dioxide and sulfur dioxide, Geneve, 2005.

[13] GODOY M.L.D.P., GODOY J.M., ROLDÃO L.A., SOLURI D.S., DONAGEMMA R.A., Coarse and fine aerosol source apportionment in Rio de Janeiro, Brazil, Atmos Environ. 2009;43:2366-2374. doi: 10.1016/j.atmosenv.2008.12.046, 2009.

[14] ENVIRONMENTAL PROTECTION AGENCY, SPECIATE 4.2 - Speciation Database Development Documentation, USA, 2009. 